\title{
Scabies Mimicking Pustular Psoriasis
}

\author{
Soundous Ben Moussa", Fatiha Bouighjdane, Meriem Abid, Ouafa Hocar, Said Amal
}

Department of Dermatology and Venereology, UHC Mohammed VI, FMPM, UCA, Marrakech, Morocco

DOI: $10.36347 /$ sasjm.2020.v06i01.001

| Received: 06.01.2020 | Accepted: 13.01.2020 | Published: 18.01.2020

*Corresponding author: Soundous Ben Moussa

\section{Abstract}

We describe the case of a 72-year-old woman with a history of generalized pruritus associated with a rash evolving over the past year. A skin biopsy was done in favor of pustular psoriasis. The patient was put on dermocorticoids with accentuation of the skin lesions. During hospitalization, a parasitological sample from the hyperkeratotic lesions and inter-digital folds was positive for the Scabei sarcope. The diagnosis of hyperkeratotic scabies was retained. The patient was put on treatment with benzyl benzoate: 3 days/week for 04 weeks. The evolution was marked by a spectacular improvement after 3 weeks of treatment with regression of the skin lesions.

Keywords: Scabies, hyperkeratosis, psoriasis, dermocorticoids.

Copyright @ 2020: This is an open-access article distributed under the terms of the Creative Commons Attribution license which permits unrestricted use, distribution, and reproduction in any medium for non-commercial use (NonCommercial, or CC-BY-NC) provided the original author and source are credited.

\section{INTRODUCTION}

Crusted or Norwegian Scabies is characterized by hyperkeratosis and crusting with the presence of innumerable mites in the skin [1]. It is a rare variant of scabies and can easily mimic other dermatologic disorders $[1,2]$. Our patient was a 72-year-old woman with hyperkeratotic scab lesions mimicking pustular psoriasis causing diagnostic difficulty.

\section{CASE REPORT}

72-year-old patient, hypertensive, consulting for generalized pruritus associated with a rash that has been evolving for 8 months in a state of general preservation context. Clinical examination revealed hyperkeratotic lesions in the buttocks and the posterior aspect of the thighs, pustular lesions on the anterior aspect of the thighs and palmoplantar keratoderma (figure1). The rest of the clinical examination was peculiar. The biological assessment of pruritus was without abnormalities. A cutaneous biopsy was made showing a parakeratosis thick and lamellar horny layer dissociated by polynuclear masses producing microabscesses with papillomatosis and broadened epidermal ridges in clubs; the mucous body shows polynuclear exocytosis with pustular appearance; in favor of pustular psoriasis. A parasitological sampling of hyperkeratotic lesions and inter-digit folds was positive for Scabei sarcophagus. The diagnosis of hyperkeratotic scabies was selected. The patient was put on benzyl benzoate treatment: 3 days/week for 4 weeks. The evolution was marked by a dramatic improvement after 3 weeks of treatment with regression of cutaneous lesions (figure 2).

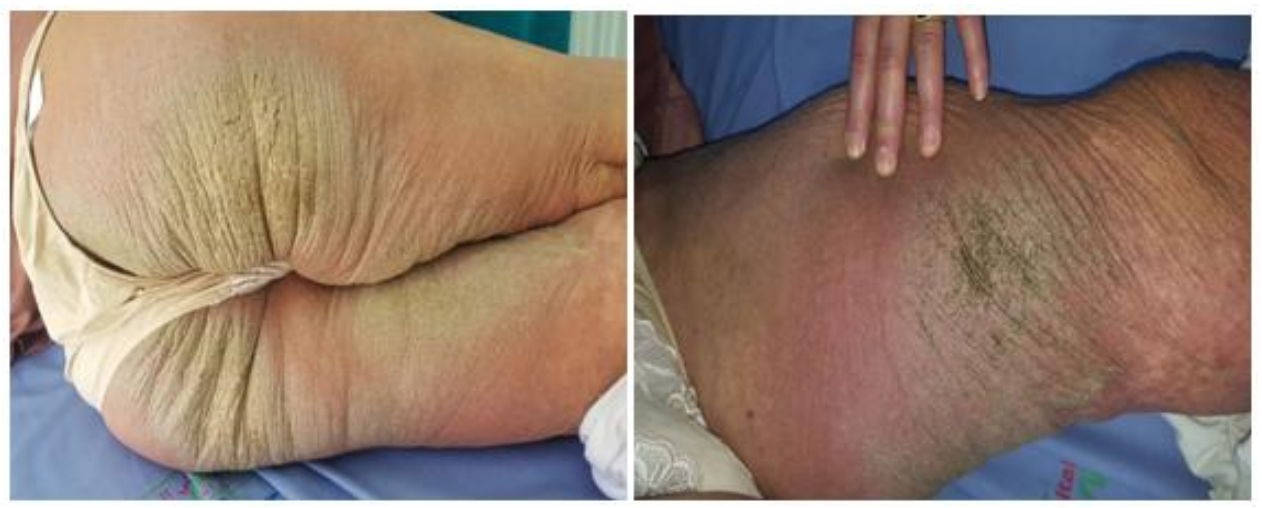

Fig-1: Clinical aspect of lesions in our patient 


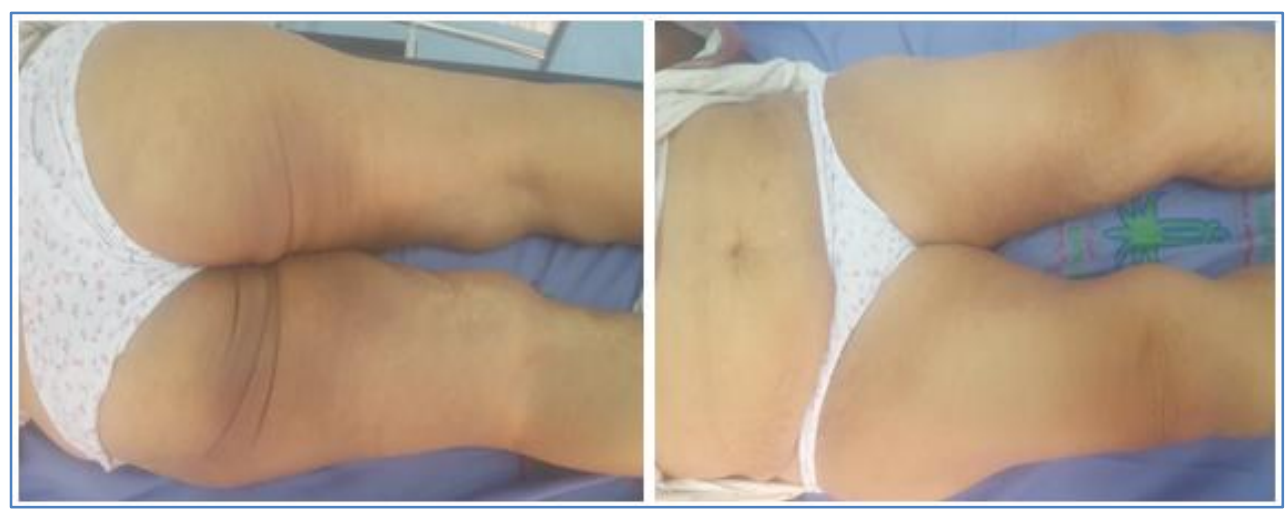

Fig-2: Spectacular evolution after 3 weeks of treatment

\section{DISCUSSION}

Crusted scabies is rare and cases are reported sporadically since the description by Boeck and Danielssen in 1848. It occurs due to altered host immune response to the infestation by the mite[1]. The condition occurs in individuals with underlying immunosuppression including human immunodeficiency virus infection, human T-cell lymphotropic virus 1 infection, and leukemia, but has also been seen in healthy patients [3]. It presents with a psoriasiform hyperkeratotic dermatosis of the hands and feet with the involvement of the nails, and an erythematous scaly eruption on the face, neck, scalp, and trunk. It is highly contagious, causing outbreaks among family members and patients in hospital wards when no preventive measures are instituted. The plaques of crusted scabies can be misdiagnosed as psoriasis, eczema, Darier's disease, contact dermatitis, ichthyosis or an adverse drug reaction [4]. Treatment of crusted scabies, particularly with nail involvement, can be difficult [5,6]. Aggressive therapy with two doses of $200 \mathrm{mg} / \mathrm{kg}$ ivermectin 2 weeks apart in combination with topical permethrin and keratolytic has been recommended by various authors [3, 4]. In our case, treatment with benzyl benzoate was effective. Also, all clothing and bed linen in contact with the patient in the preceding $48-72 \mathrm{~h}$ should be washed at $60^{\circ}[3,4]$. Our case highlights the importance of skin examination, keeping an open mind for the diagnosis of scabies in the absence of any obvious risk factors.

\section{CONCLUSION}

Common and crusted scabies are re-emerging diseases in economically stable countries. Scabies crusty occur in fragile patients and are associated with morbidity and mortality much higher than the ordinary form. Its treatment is long and restrictive, but the effectiveness of management is essential for epidemic control. Our case highlights the importance of skin examination, keeping an open mind for the diagnosis of scabies in the absence of any obvious risk factors.

\section{REFERENCES}

1. Karthikeyan K. Crusted scabies. Indian J Dermatol Venereol Leprol. 2009; 75:340-7.

2. Orkin M. Special forms of scabies. In: Orkin M, Maibach HI, Parisch LC, Schwartzman RM, editors. Scabies and Pediculosis. Philadelphia: Lippincott; 1977: 23-30

3. Heukelbach J, Feldmeier H. Scabies. Lancet. 2006; 367: 1767-74

4. Ohtaki Chosidow O. Scabies. N Engl J Med. 2006; 354: 1718-27.

5. Roberts LJ, Huffman SE, Walton SF, Currie BJ. Crusted scabies. Clinical and immunological findings in seventyeight patients and a review of literature. J Infect. 2005; 50: 375-81.

6. Ohtaki N, Taniguchi H, Ohtomo H. Oral Ivermectin treatment in two cases of scabies: effective in crusted scabies induced by corticosteroid but ineffective in nail scabies. J Dermatol. 2003; 30: 411-16. 